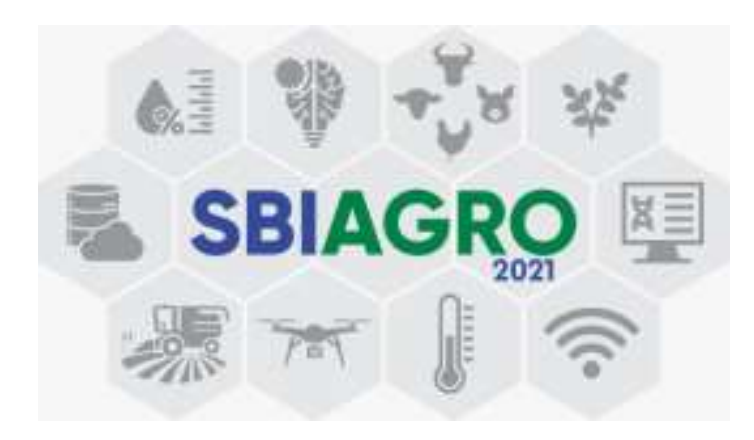

\title{
Redes Neurais na Simulação de Condições Climáticas Potenciais ao Cultivo de Bambu no Brasil
}

\author{
João Antonio Lorençone ${ }^{1}$, Lucas E. de O. Aparecido² ${ }^{2}$ Pedro Antonio Lorençone ${ }^{1}$, \\ Guilherme Botega Torsoni ${ }^{1}$ \\ ${ }^{1}$ Instituto Federal de Mato Grosso do Sul (IFMS) \\ Naviraí - MS - Brazil \\ ${ }^{2}$ Instituto Federal do Sul de Minas (IFSULDEMINAS) \\ Muzambinho - MG - Brazil \\ joao.lorenconedestudante.ifms.edu.br, \\ lucas.aparecido@muz. ifsuldeminas.edu.br, \\ pedro.lorenconedestudante.ifms.edu.br, \\ guilherme.torsoni.ifms.edu.br
}

\begin{abstract}
This study aimed to perform the agricultural zoning of climatic risk for bamboo in Brazil by means of artificial neural networks. It was used climatic data of air temperature $\left(T A I R,{ }^{\circ} C\right)$ and rainfall $(P)$. The Feed Forward Artificial Neural Network, Multilayer Perceptron (MLP) with backpropagation learning algorithm for multilayers was employed. The agroclimatic zoning allowed the classification of regions by climatic suitability and showed that $71 \%$ of the national territory was suitable for bamboo cultivation. The use of the neural network allowed an accurate and fast classification of climate suitability.
\end{abstract}

Resumo. Esse estudo teve como objetivo realizar o zoneamento agrícola de risco climático do bambu no Brasil por meio de redes neurais artificiais. Foram utilizados dados climáticos de temperatura do ar (TAIR, $\left.{ }^{\circ} \mathrm{C}\right)$ e precipitação pluviométrica (P). Foi empregado a Rede Neural Artificial Feed Forward, Multilayer Perceptron (MLP) com algoritmo de aprendizagem "backpropagation" para multicamadas. O zoneamento agroclimático permitiu a classificação das regiões por aptidão climática e demonstrou que 71\% do território nacional foram aptos para o cultivo do bambu. O uso da rede neural permitiu uma classificação precisa e rápida das aptidões climáticas.

\section{Introdução}

O bambu destaca-se no comércio internacional pela sua utilização em diversos fins, como na produção de papel, carvão, artesanato e como substituto a madeira na construção civil. 
A biomassa do bambu tem grande potencial para a produção de bioenergia por apresentar alta taxa de crescimento, bem como alto teor de celulose, alto valor calorífico bruto e baixo teor de cinzas. Grande parte dessas caracteristicas do bambu são influênciadas pelo clima da região.

O Zoneamento agrícola de risco climático (ZARC) tem sido uma ferramenta fundamental para minimizar os riscos relacionados aos fenômenos climáticos adversos [de Oliveira Aparecido et al., 2018]. O ZARC pode fornecer informações para identificar as melhores datas de plantio, colheita, assim como identificar os períodos que as condições climáticas atendem às necessidades de um determinado do cultivo [Gelcer et al., 2018]. Neste contexto, objetivou-se realizar o ZARC para a cultura do bambu usando redes neurais, e assim minimizar os riscos de perdas dos produtores por adversidades climáticas incontroláveis.

\section{Material e Métodos}

Este trabalho foi realizado utilizando dados climáticos do Brasil, foram utilizados dados de temperatura do ar e precipitação pluviométrica de 4.947 estações meteorológicas do Brasil, entre 1950 a 2016. Esta série temporal climática foi coletada pelo Instituto Nacional de Meteorologia do Brasil (INMET).

As áreas aptas para o cultivo do bambu foram definidas a partir dos dados climáticos de Temperatura do ar (TAIR) média anual $\left({ }^{\circ} \mathrm{C}\right)$, precipitação total anual $(\mathrm{P}, \mathrm{mm}$ ano-1) e precipitação total do inverno (Pwinter, mm ano-1). Ao se conhecer as necessidades térmico-hídricas do bambu, foram estabelecidas as classes de aptidão climática para cultura.

Foram consideradas as regiões aptas climaticamente para o cultivo quando a temperature média anual do $\operatorname{ar}(\mathrm{T})$ variou entre 18 e $35^{\circ} \mathrm{C}$, a precipitação pluvial $(\mathrm{P})$ apresentou valores entre 500 a $2800 \mathrm{~mm} \mathrm{ano}^{-1}$ ou Precipitação durante o inverno (Pwinter) entre 90 e 180 $\mathrm{mm}$ ano-1. A ocorrência de $\mathrm{T}$ acima de $35{ }^{\circ} \mathrm{C}$ foi considerada inapta, pois acima dessa temperatura do ar as plantas tendem a reduzir a fotossíntese líquida, pois a respiração é maior do que o processo fotossintético, inviabilizando a plantação da cultura. Ainda as áreas nas quais apresentaram $\mathrm{T}$ abaixo de $10^{\circ} \mathrm{C}$ foram consideradas inaptas.

Também foram estabelecidas as seguintes restrições: $1^{\mathrm{a}}=\mathrm{T}$ entre 10 e $18{ }^{\circ} \mathrm{C}$, o crescimento do cultivo é retardado devido ao baixo acúmulo de graus dias durante o ciclo; $2^{\mathrm{a}}=\mathrm{P}<500 \mathrm{~mm}$ ano-1 ou Pwinter $<$ que $90 \mathrm{~mm}$ ano-1 (desenvolvimento irregular devido ao déficit hídrico); $3^{\mathrm{a}}=\mathrm{P}>2800 \mathrm{~mm}$ ano-1 ou Pwinter $>$ de $180 \mathrm{~mm}$ ano-1 (excesso de umidade), alto índice de doenças nos cultivos.

Com base nesses critérios de classificações, foi criado o vetor $\mathrm{Yj}$ para calibração do modelo, sendo o mesmo representado pela equação 1 .

$\mathrm{Y}_{j}=\left[y_{1} \ldots y_{4947}\right](y \in\{A P T O, I N A P T O \ldots, \ldots$ RESTRIÇÕES $\})$

Empregou-se a Rede Neural Artificial Feed Forward, Multilayer Perceptron (MLP), onde os valores de entradas foram as variáveis climáticas selecionadas ( $\mathrm{T}$ e $\mathrm{P}$ ) e a saída foram às classes do zoneamento agrícola (output). O aprendizado da MLP foi o supervisionado e o algoritmo de aprendizagem foi o backpropagation para multicamadas.

Uma MLP com $\mathrm{N}$ camadas, $\mathrm{H}$ neurônios escondidos e um neurônio de saída pode ser expresso pela equação 2: 
em que: $Z O N I N G$ = é a saída da RNA; Oh = valor de saída do h-ésimo neurônio escondido; $\mathrm{W} 0$ = são valores iniciais do algoritmo de treinamento da RNA; $\mathrm{Wh}=$ são os pesos sinápticos entre os neurônios escondidos da RNA.

Para realizar a calibração do algoritmo da rede neural foram utilizados $35 \%$ dos dados climáticos das localidades, sendo que nesses locais o zoneamento agrícola foi feito de maneira manual, utilizando o software Excel. Com a rede neural calibrada e acurada, foi estabelecida a classificação climática para o bambu para todas as 4.947 estações climáticas do Brasil..

\section{Discussão e Resultados}

O ZARC para a cultura do bambu demonstrou que $71 \%$ do Brasil é apto climaticamente ao cultivo (Figura 1). Os Estados brasileiros que foram classificados como aptos em sua totalidade foram o Mato Grosso do Sul, Goiás, Tocantins, Rio de Janeiro, Espírito Santo, Sergipe, Alagoas, Ceará, Piauí, Maranhão, Rondônia e Acre (Figura 1). Essa enorme faixa de regiões aptas ocorre devido o cultivo do bambu apresentar uma ampla aptidão climática. Estas regiões com condições climáticas ideais ao cultivo associadas aos fatores do manejo, apresentam elevadas produtividades e consequentemente, um maior retorno econômico aos produtores agrícolas. As regiões que apresentam restrições por baixas TAIR representaram apenas $11 \%$ do território brasileiro (Figura 2), sendo parte da região Sul do Brasil (região do Planalto e Norte de Santa Catarina, região Sul do Paraná e Sul do Rio Grande do Sul) e o Sul de Minas Gerais. Ressalta-se que nestas regiões o cultivo do bambu pode ser implantado, entretanto, apresentar um crescimento retardado, em função do baixo acúmulo de determinada quantidade de energia, denominada graus-dia acumulados, que o cultivo vai apresentar [Chen et al. 2018].

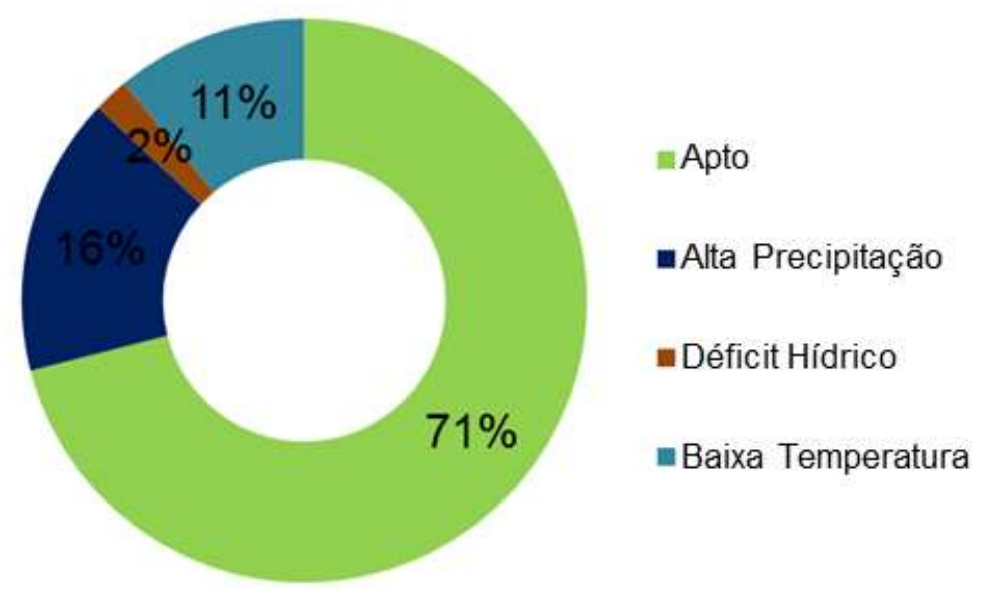

Figure 1. Porcentagem das áreas para cada classe de zoneamento agrícola de risco climático do bambu no Brasil. 


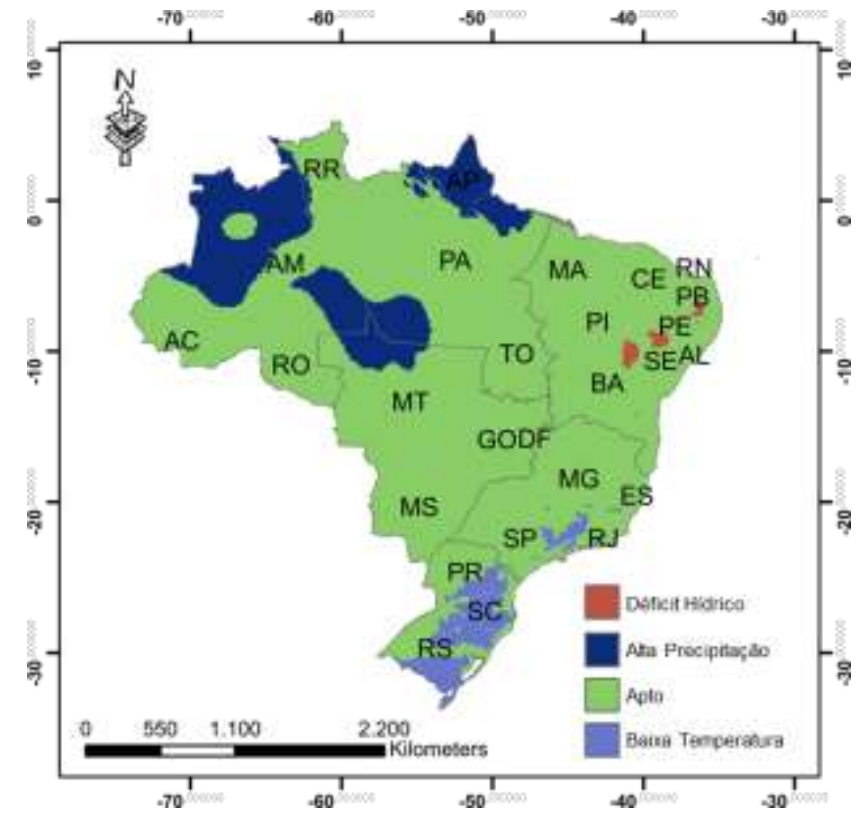

Figura 2. Zoneamento agrícola de risco climático da cultura do bambu para o Brasil.

\section{Conclusões}

A rede neural é uma ferramenta eficiente na realização de zoneamento agrícola de risco climático, permitindo uma classificação rápida e acurada das aptidões climáticas.

O zoneamento agrícola de risco climático demonstra que $71 \%$ do território brasileiro são aptos climaticamente ao cultivo do bambu.

As regiões com restrição foram parte do Sul do Brasil, por apresentar baixas TAIR e parte da região no Norte por apresentar elevadas $\mathrm{P}$ que proporcionam elevados índices de doenças

\section{References}

Chen, S., Jiang, H., Cai, Z., Zhou, X., \& Peng, C. (2018). The response of the net primary production of Moso bamboo forest to the On and Off-year management: A case study in Anji County, Zhejiang, China. Forest Ecology and Management, 409, 17. https://doi.org/10.1016/j.foreco.2017.11.008

de Oliveira Aparecido, L. E., Moreto, V. B., de Souza Rolim, G., da Silva Cabral de Moraes, J. R., Valeriano, T. T. B., \& de Souza, P. S. (2018). Climatic potential for summer and winter wine production: Climatic potential for summer and winter wine production. Journal of the Science of Food and Agriculture, 98(4), 12801290. https://doi.org/10.1002/jsfa.8575

Gelcer, E., Fraisse, C. W., Zotarelli, L., Stevens, F. R., Perondi, D., Barreto, D. D., ... Southworth, J. (2018). Influence of El Niño-Southern oscillation (ENSO) on agroclimatic zoning for tomato in Mozambique. Agricultural and Forest Meteorology, 248, 316-328. https://doi.org/10.1016/j.agrformet.2017.10.002 